\title{
Chorioamnionitis is associated with placental transmission of human immunodeficiency virus-1 subtype $E$ in the early gestational period
}

Lertlakana Bhoopat ${ }^{1}$, Surapan Khunamornpong ${ }^{1}$, Pannee Sirivatanapa ${ }^{2}$, Tat Rithaporn ${ }^{1}$, Piyaporn Lerdsrimongkol ${ }^{1}$, Paul S Thorner ${ }^{3}$ and Tanin Bhoopat ${ }^{1}$

${ }^{1}$ Department of Pathology, Faculty of Medicine, Chiang Mai University, Chiang Mai, Thailand; ${ }^{2}$ Department of Obstetrics and Gynecology, Faculty of Medicine, Chiang Mai University, Chiang Mai, Thailand and ${ }^{3}$ Division of Pathology, Hospital for Sick Children, and Department of Laboratory Medicine and Pathobiology, University of Toronto, Toronto, Canada

\begin{abstract}
The frequency and the cellular basis for HIV-1 transmission from mother to child in the early gestational period are poorly understood. We compared the placentas of 24 women seropositive for HIV-1 subtype $E$ and who had not received any antiretroviral drugs, to placentas of 25 seronegative women. All placentas were obtained during therapeutic abortion at 6-23 weeks gestation. Placentas and fetal organs were examined by routine light microscopy, immunostaining for p24 capsid protein, and in situ PCR to localize which cells were infected with HIV-1 subtype $E$. The number of previous abortions was not a factor in placental HIV infection since this number was higher in seronegative women $(P<0.01)$. There were no significant differences between the placentas of the two groups with respect to presence of chorioamnionitis, villitis, villous stromal fibrosis, infarction, abnormal villous maturation, deciduitis or decidual necrosis. HIV-1 subtype E was detected in up to $83 \%$ of placentas, either by immunostaining or in situ PCR, in trophoblast, villous stromal cells, Hofbauer cells, decidual and decidual glandular epithelium. Fetal organs were positive for HIV in $30 \%(6 / 20)$ of cases. There was a significant association between transmission of HIV to the fetus and the histologic findings of chorioamnionitis, plasmacellular deciduitis and decidual cell necrosis. This is the first report showing an association of chorioamnionitis with early in utero transmission of HIV-1 subtype E. This may help explain the cases of in utero transmission that persist despite antiretroviral prophylaxis, given that therapy is started in the late gestational period.
\end{abstract}

Modern Pathology (2005) 18, 1357-1364. doi:10.1038/modpathol.3800418; published online 22 April 2005

Keywords: placenta; chorioamnionitis; HIV-1 subtype E; fetal transmission

The human immunodeficiency virus (HIV) epidemic over the last 20 years has become a growing cause of infant mortality. Before antiretroviral therapy, the risk of a mother with HIV giving birth to an infected newborn was $20-30 \%$ for the first child, ${ }^{1}$ and $50-65 \%$ for subsequent children. ${ }^{2}$ Antiretroviral prophylaxis administered before birth has increased the chances that a child of an infected mother will be born free of HIV. Treatment is usually initiated near to the time of

Correspondence: Dr L Bhoopat, MD, Faculty of Medicine, Department of Pathology, Chiang Mai University, Chiang Mai 50200, Thailand.

E-mail: lbhoophat@mail.med.cmu.ac.th

Received 17 August 2004; revised 5 January 2005; accepted 21

February 2005; published online 22 April 2005 birth based on the concept that most pediatric HIV type 1 infections occur at or near birth. ${ }^{3-6}$ This is at variance with earlier hypotheses that prenatal transmission is responsible for most pediatric HIV infections. ${ }^{1,7,8}$

Transmission of HIV may occur due to transplacental viral infection, exposure to maternal blood at the time of delivery, and/or postnatal exposure to maternal secretions. It is believed that the placenta plays a major role in protecting against perinatal HIV transmission, ${ }^{9}$ but most reports of perinatal HIV transmission have not evaluated placental pathology. ${ }^{10-16}$ Studies on HIV in Africa have concluded that chorioamnionitis is a risk factor for perinatal HIV transmission ${ }^{17-20}$ and infant mortality ${ }^{21}$ but whether it is a factor in the early gestational period is not clear. 
There is evidence that fetal infections can occur early, anywhere from 8 to 28 weeks gestational age.,22-25 HIV antigens and genome have been detected in trophoblast, Hofbauer cells, and endothelial cells in the placenta as early as 8-week gestation. ${ }^{26}$ These cases of prenatal transmission are probably transplacental but could occur via an ascending route, that is, chorioamnionitis. Moreover, these reports are based on HIV-1 subtype B and whether the same is true for subtype $\mathrm{E}$ has not been well studied. HIV-1 subtype $\mathrm{E}$ is found predominantly in Thailand and other Southeast Asian countries and is spread mainly by heterosexual transmission. ${ }^{27}$ In an attempt to address some of the above issues, we examined placentas from the early gestational period in mothers with HIV-1 infection subtype E. We sought to determine what pathologic changes were associated with HIV-1 infection at this gestational age and which cells were infected with the virus.

\section{Materials and methods}

\section{Patients and Controls}

Placentas of 24 seropositive, HIV-1-infected women and 25 seronegative women (controls) were collected at the time of therapeutic abortion at Maharaj Nakorn Chiang Mai Hospital in Chiang Mai, Thailand. Fetal organs were available in 20/24 seropositive cases and in 20/25 seronegative cases. Seropositivity was determined by ELISA and confirmed by Western blot analysis. None of the women had received zidovudine or any other antiretroviral drugs. The clinical information was collected from chart review and included: maternal age, gestational age, pregnancy parameters, occupation, indication for pregnancy termination, and methods for termination of pregnancy.

\section{Histopathology}

Multiple tissue samples were collected from all placentas, fixed in neutral-buffered formalin and embedded in paraffin. Sections $(3 \mu \mathrm{m})$ were mounted on poly-L-lysine-coated slides. Sections were examined by routine light microscopy after staining with: Harris hematoxylin-eosin, Gram (Brown-Hopps), mucicarmine, periodic acid-Schiff, Warthin-Starry, Gomori methenamine silver and Ziehl-Neelson. Microscopic features were evaluated by a team of pathologists without knowledge of HIV status of the mother or fetus. A semiquantitative grading of chorioamnionitis was used, based on the number of neutrophils infiltrating the chorionic plate. $^{28}$ Cases with $\leq 10$ inflammatory cells per $\times 40$ field in areas of involvement were designated as 'mild to moderate' and cases with >10 inflammatory cells per $\times 40$ field in areas of involvement as 'severe'. Other histologic features that were evaluated included villitis, villous stromal fibrosis, placental infarction, abnormal villous maturity, deciduitis and decidual necrosis.

\section{Data Analysis}

Statistical comparisons between clinical characteristics of HIV-seropositive and seronegative women were carried out using the standard Student's $t$-test and Pearson's $\chi^{2}$. The two-tailed Fisher's exact test was used to evaluate differences in placental pathology between HIV-infected women who transmitted or did not transmit HIV to the fetus. Values of 0.05 or less were considered to be significant.

\section{Immunohistochemistry for HIV-1 p24 Capsid Proteins}

After standard deparaffinization, sections underwent antigen retrieval in sodium acetate buffer for $13 \mathrm{~min}$ in a microwave. After this, endogenous peroxidase was quenched by $3 \%$ hydrogen peroxide, and nonspecific binding was blocked with bovine serum albumin (BSA) and nonfat milk protein. Sections were then incubated with a 1:5 dilution of a mouse monoclonal antibody against HIV capsid protein (p24) from Dako (Carpinteria, CA, USA) for $1 \mathrm{~h}$ at room temperature $\left(25^{\circ} \mathrm{C}\right)$. Following washing, a biotinylated secondary antibody was added for $30 \mathrm{~min}$, and then a streptavidin peroxidase complex (LSAB kit, Dako) for $30 \mathrm{~min}$. The reaction was developed using 3-3' diaminobenzidine and hydrogen peroxide. Development of brown color signified a positive reaction. Negative controls included substituting the p24 antibody with nonspecific murine IgG, and staining noninfected placentas from seronegative mothers for p24 protein.

\section{In Situ Polymerase Chain Reaction (In Situ PCR)}

In situ PCR was performed using $12.5 \mu \mathrm{M}$ of primers: SK38 (sense) (5' ATA ATC CAC CTA TCC CAG TAG GAG AAA T), SK39 (antisense) (5' TTT GGT CCT TGT CTT ATG TCC AGA ATG C), TN01 (sense) $\left(5^{\prime}\right.$ GGA AGT GAC ATA GCA GG) and TN02 (antisense) (5' CTA CAT AGT CTC TGA AGG G), $0.2 \mathrm{mM}$ of each dNTPs, $0.15 \mathrm{U}$ of Taq DNA polymerase and $1 \times$ PCR buffer. Primers SK38 and SK39 contain sequences shared by subtypes B and E, while primers TN01 and TN02 are specific for subtype E. ${ }^{29}$ The mixture was contained in $15 \mu \mathrm{l}$ that allowed the entire tissue section to be covered, following which a glass coverslip was added and sealed with clear nail polish. The amplification process was achieved using Hybaid in situ PCR thermocycler (Franklin, MD, USA) under the following conditions: $94^{\circ} \mathrm{C}$ for $30 \mathrm{~s}, 61^{\circ} \mathrm{C}$ for $1 \mathrm{~min}$ and $72^{\circ} \mathrm{C}$ for $1 \mathrm{~min}$, for 30 cycles. The coverslip was removed and the slide washed in $2 \times$ SSC for $2 \mathrm{~min}$ and PBS for a further $2 \mathrm{~min}$. 
Subsequently, the sections were postfixed in freshly made $4 \%$ paraformaldehyde for $5 \mathrm{~min}$, dehydrated in graded alcohol and air-dried. Sections were then incubated overnight at room temperature with the biotinylated probe, TN03 (5' ATC CTG GGA TTA AAT AAA ATA GTA AGA ATG TAT AGC CC) that hybridizes to the PCR reaction product. The TN03 probe was then visualized by tyramide amplification using the TSA-Indirect ISH kit (NEN Life Science Products, UK) according to the manufacturer's protocol. Briefly, sections are blocked for $30 \mathrm{~min}$ in TNB buffer at room temperature, then incubated for $30 \mathrm{~min}$ in horseradish peroxidase-conjugated streptavidin), followed by 5 min in biotin tyramide solution. For visualization of the signal, sections were incubated for $30 \mathrm{~min}$ in horseradish peroxidase-conjugated streptavidin. Diaminobenzidine was used as the chromogen and hematoxylin as a counterstain.

\section{HIV Subtyping}

HIV subtyping was carried out using the PCR on DNA extracted from peripheral blood samples. The portion of the genome amplified included the dimerization initiation site (DIS) loop sequence present in infectious recombinant provirus. The DIS loop and flanking sequences were amplified from cell lysates by using a $27 \mathrm{bp}$ upstream (sense) primer DIS1 (5'-AAATCTCTAGCAGTGGCGCCC GAACAG-3') and a $24 \mathrm{bp}$ downstream (antisense) primer DIS2 (5'-CTCTCCTTCTAGCCTCCGCTAGTC $-3^{\prime}$ ) based on published sequences. ${ }^{30}$ A 165-bp PCR fragment was generated after 30 cycles of PCR amplification following published conditions. ${ }^{30} \mathrm{~A}$ $10 \mu \mathrm{l}$ sample of the PCR mixture was subjected to digestion with BssHII, which recognizes the sequence GCGCGC, found in HIV-1 subtype B but not $\mathrm{E}$, and with ApaLI, which recognizes the sequence GTGCAC, found in HIV-1 subtype E but not B. ${ }^{30}$ Positive controls were known infected peripheral blood mononuclear cells of both subtypes.

\section{Results}

Comparison of Clinical Features of HIV Seropositive vs Seronegative Women

Seropositive and seronegative women did not differ significantly in age, primiparity status, occupation, or hepatitis B coinfection. Similar methods of pregnancy termination were used in both groups. Although the mean gestational age in the seropositive group was $\sim 4$ weeks less than the seronegative group (12.4 compared to 16.4), the range was comparable in the seronegative (6-23 weeks) and seropositive (8-20 weeks) groups. Of interest, the number of women having more than one previous therapeutic abortion was higher in the seronegative group $(9 / 25)$ compared to $1 / 24$ in the seropositive group $(P<0.01)$.

\section{Pathology of Aborted Placentas from HIV-Seropositive and Seronegative Women}

Histopathologic findings of placentas obtained from seropositive and seronegative women are shown in Table 1. There were no significant differences with respect to presence of chorioamnionitis, villitis, villous stromal fibrosis, infarction, abnormal villous maturation, deciduitis or decidual necrosis. Chorioamnionitis was actually more frequent in seronegative women although this difference did not reach statistical significance. Severe inflammation as judged by the number of inflammatory cells was similar in both groups, and lesser degrees of inflammation were actually more common in the seronegative group $(P<0.05)$.

\section{Immunohistochemical Results for HIV Capsid Protein Staining in Placentas and Fetal Organs}

Immunohistochemical and in situ PCR studies were conducted on all 24 seropositive and 25 seronegative aborted placentas. The results in placentas from seropositive patients are detailed in Table 2 .

Table 1 Pathological findings in placentas of HIV seropositive and seronegative women

\begin{tabular}{|c|c|c|c|c|c|}
\hline \multirow{2}{*}{$\begin{array}{l}\text { Findings } \\
\text { Chorioamnionitis }\end{array}$} & \multicolumn{2}{|c|}{ HIV seropositive $(\mathrm{n}=24)^{\mathrm{a}}$} & \multicolumn{2}{|c|}{ HIV seronegative $(\mathrm{n}=25)^{\mathrm{a}}$} & \multirow{2}{*}{$\frac{\text { P-value }}{\mathrm{NS}}$} \\
\hline & $5 / 20$ & $25 \%$ & $10 / 24$ & $42 \%$ & \\
\hline (a) Mild to moderate inflammation & $0 / 20$ & $0 \%$ & $4 / 24$ & $16 \%$ & $<0.05$ \\
\hline (b) Severe inflammation & $5 / 20$ & $25 \%$ & $6 / 24$ & $25 \%$ & NS \\
\hline Villitis & $1 / 24$ & $4 \%$ & $3 / 25$ & $12 \%$ & NS \\
\hline Villous stromal fibrosis & $6 / 24$ & $25 \%$ & $8 / 25$ & $32 \%$ & NS \\
\hline Placental infarction & $5 / 24$ & $21 \%$ & $6 / 25$ & $24 \%$ & NS \\
\hline Abnormal villous maturity & $1 / 24$ & $4 \%$ & $0 / 25$ & $0 \%$ & NS \\
\hline Acute deciduitis & $11 / 24$ & $46 \%$ & $13 / 25$ & $52 \%$ & NS \\
\hline Plasmacellular deciduitis & $4 / 24$ & $17 \%$ & $4 / 25$ & $16 \%$ & NS \\
\hline Decidual necrosis & $10 / 24$ & $41 \%$ & $14 / 22$ & $64 \%$ & NS \\
\hline
\end{tabular}

${ }^{\mathrm{a}}$ The number of cases in each finding varied due to availability of tissues received.

NS $=$ not significant. 
Table 2 p24 capsid protein (immunohistochemistry) and HIV proviral DNA (in situ PCR) in placentas from seropositive women

\begin{tabular}{|c|c|c|c|c|}
\hline \multirow[t]{2}{*}{ Placental and fetal tissues } & \multicolumn{2}{|c|}{ Immunostaining for HIV capsid protein } & \multicolumn{2}{|c|}{ In situ PCR for $H I V-1 D N A$} \\
\hline & \# of Cases & Percentage & \# of Cases & Percentage \\
\hline Decidua & $12 / 24$ & 50 & $7 / 24$ & 29 \\
\hline Decidual glandular epithelium & $10 / 24$ & 42 & $20 / 24$ & 83 \\
\hline Endothelium & $15 / 24$ & 62 & $2 / 24$ & 8 \\
\hline \multicolumn{5}{|l|}{ Trophoblast } \\
\hline (a) Intermediate trophoblast & $4 / 24$ & 17 & $5 / 24$ & 21 \\
\hline (b) Syncytiotrophoblast & $6 / 24$ & 25 & $12 / 24$ & 50 \\
\hline (c) Cytotrophoblast & $9 / 24$ & 38 & $8 / 24$ & 33 \\
\hline Villous stroma & $7 / 24$ & 29 & $9 / 24$ & 38 \\
\hline Villous macrophage (Hofbauer cell) & $8 / 24$ & 33 & $4 / 24$ & 17 \\
\hline Amnion & $0 / 24$ & 0 & $5 / 24$ & 21 \\
\hline Fetal components of placenta (overall) & $16 / 24$ & 67 & $15 / 24$ & 62 \\
\hline
\end{tabular}
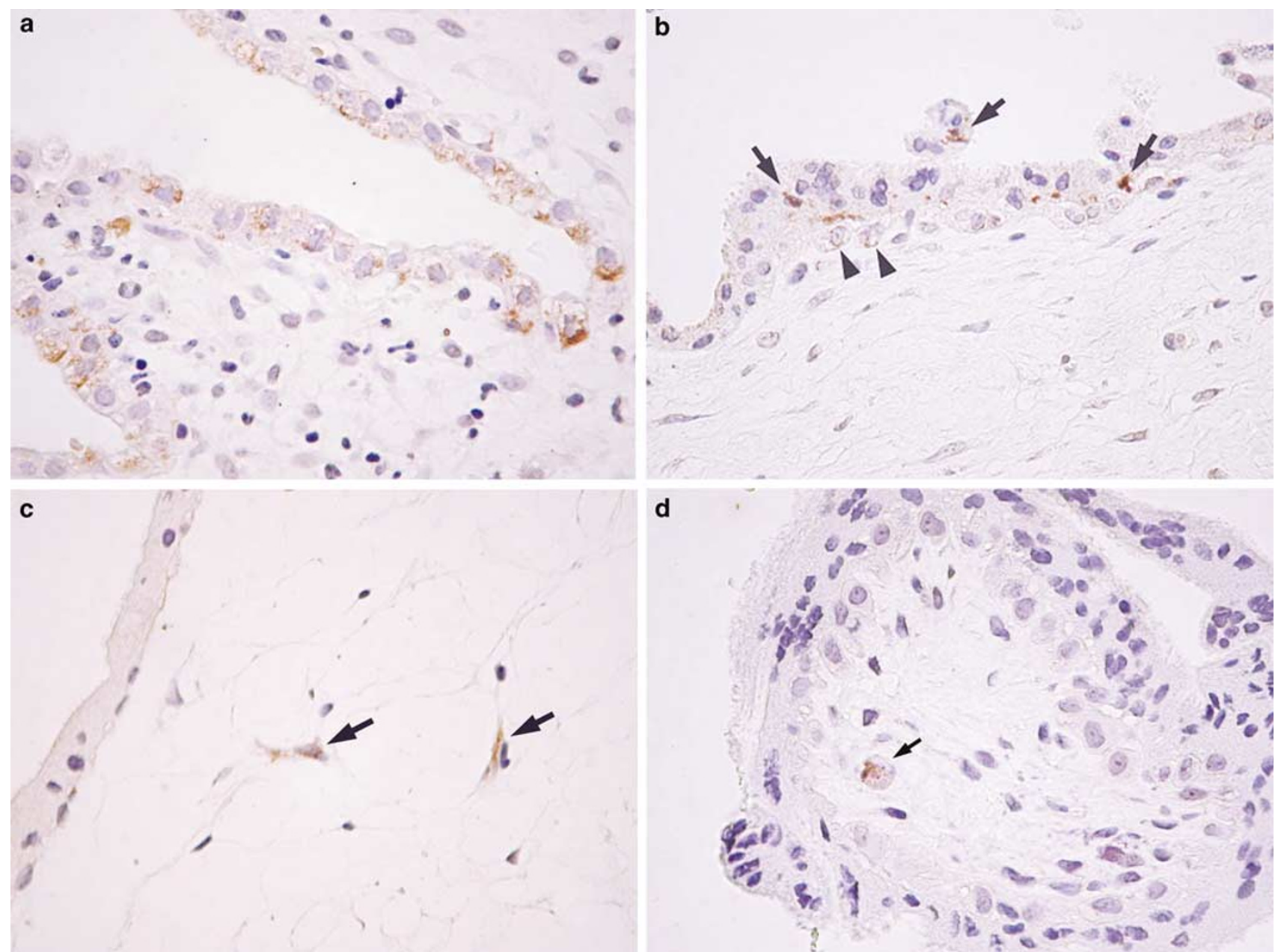

Figure 1 Immunohistochemical staining for HIV p24 antigen in placenta. Positive cytoplasmic staining is detected in (a) decidual glandular epithelium, (b) syncytiotrophoblast cells (arrows) and cytotrophoblast cells (arrowheads) (c) villous stromal cells (arrows) and (d) Hofbauer cells (arrow) (original magnification $\times 400$ ).

Seronegative cases were uniformly negative. HIV was detected in the cytoplasm of decidual cells, decidual glands and/or maternal endothelial cells in over $60 \%$ of cases by immunostaining and over $80 \%$ of cases by in situ PCR (Figure 1a). Similarly, positive staining was noted in the fetal components of the placenta in two-thirds of cases by immunostaining and over $60 \%$ of cases by in situ PCR. 
Infected cells varied from placenta to placenta, and with the detection technique, but included trophoblast (intermediate, syncytiotrophoblast, and cytotrophoblast) (Figure 1b), villous stromal cells (Figure 1c) and Hofbauer cells (Figure 1d). Fetal organs other than placenta were available in 20 of 24 seropositive cases. Four of these cases (20\%) revealed HIV p24 antigen in fetal organs including lung, brain and intestine (Table 3 and Figure 2a and b). Control fetal tissues in the non-HIV-infected group were all negative.

\section{HIV Proviral DNA Expression in Nonplacental Fetal Organs}

HIV proviral DNA expression by in situ PCR revealed positive signals in four out of $20(20 \%)$ fetal specimens (Table 3 and Figure 2c). Two of the cases were also positive by immunohistochemistry. All control fetal tissues in the non-HIV-infected group revealed no positive signal. When combined with immunohistochemical reactivity of HIV p24

Table 3 p24 capsid protein (immunohistochemistry) and HIV proviral DNA (in situ PCR) in nonplacental fetal tissues

\begin{tabular}{ccccc}
\hline Case \# & Gestational & Fetal & p24 & HIV \\
& age (weeks) & tissue & capsid & proviral \\
& & protein & DNA \\
& & & \\
\hline
\end{tabular}

\begin{tabular}{lllll}
\hline 1 & 12 & Glial cells & - & + \\
2 & 18 & Intestinal epithelium & + & - \\
& & Mesenchyme & - & + \\
3 & 19 & Alveolar epithelium & + & - \\
4 & 11 & Alveolar epithelium & + & + \\
5 & 20 & Glial cells & + & - \\
6 & 16 & Glial cells & - & + \\
\hline
\end{tabular}

antigen, the positive HIV fetuses increased to 6 of 20 cases $(30 \%)$. The earliest positive gestational age was 11 weeks.

\section{HIV Subtyping in Placentas of Seropositive Cases}

The antibody used for immunohistochemical staining for HIV capsid protein does not distinguish subtypes of HIV-1, nor does the in situ PCR used in this study. Therefore, HIV subtyping was carried out using a molecular genetic approach. All 24 HIVseropositive patients in this study showed infection with subtype E of the HIV-1 virus.

\section{Comparison of Pathological Findings of Placentas in Cases With and Without HIV Transmission to the Fetus}

The 6/20 fetal specimens that showed HIV p24 antigen and/or proviral DNA were considered to be the cases with HIV transmission, while the remaining 14 specimens that showed negative result for both HIV p24 and proviral DNA were the nontransmission group. The pathological findings in the placentas for these two groups of cases are listed in Table 4. When comparing fetuses with and without HIV transmission, there was no significant difference between the presence of villitis, villous stromal fibrosis, infarction, and abnormal villous maturation in placentas. Significant differences were noted with respect to the presence of chorioamnionitis, decidual cell necrosis and plasmacellular deciduitis, which occurred more often in cases with fetal HIV transmission. Acute deciduitis was also more frequent in cases with HIV transmission, but this association did not reach statistical significance $(P=0.07)$.
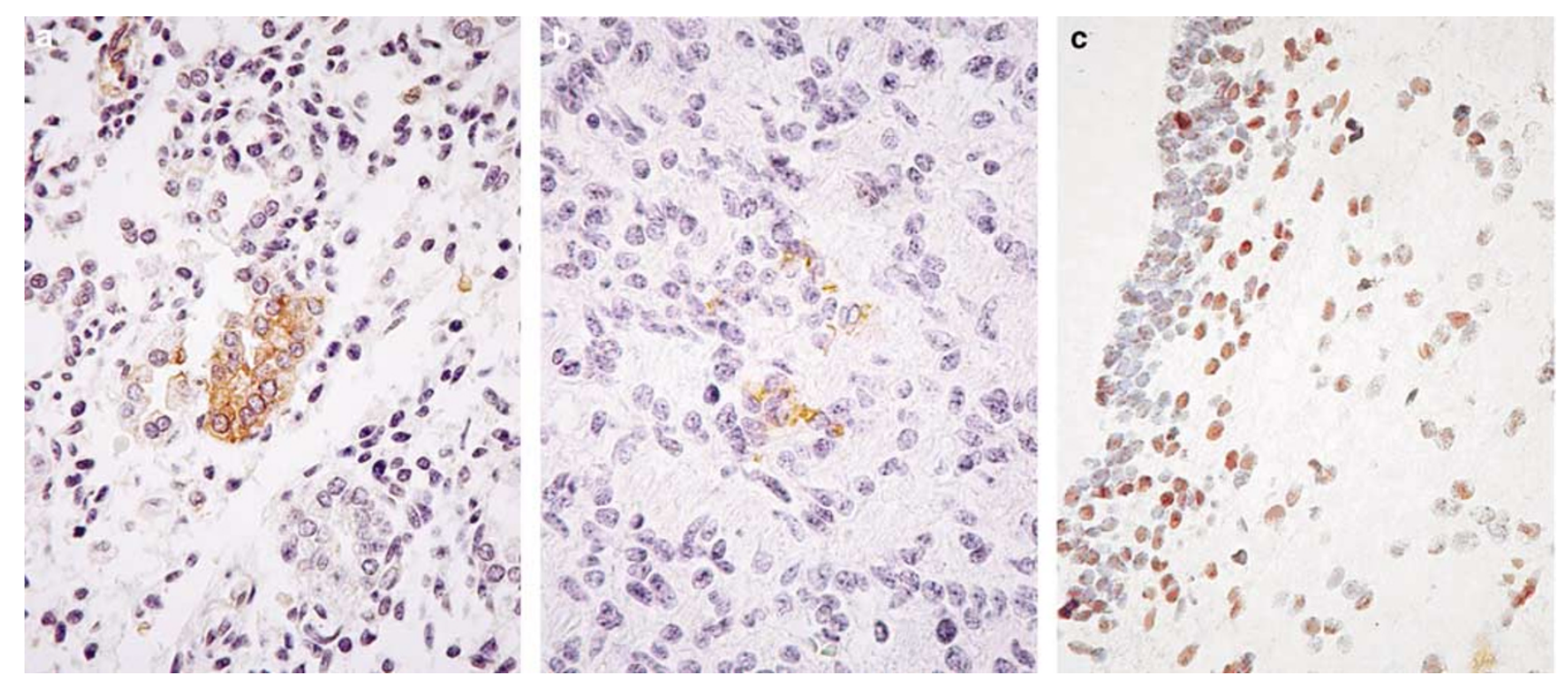

Figure 2 Detection of HIV in fetal organs. HIV-1 was detected by immunohistochemical staining for p24 antigen (a and b) and by in situ PCR for HIV-1 proviral DNA (c). Positive signals are seen in fetal lung (a) and fetal brain (b and c) (original magnification $\times 400$ ). 
Table 4 Pathological findings in placentas with and without histologic evidence of HIV transmission

\begin{tabular}{|c|c|c|c|c|c|}
\hline \multirow{2}{*}{$\begin{array}{l}\text { Findings } \\
\text { Chorioamnionitis }\end{array}$} & \multicolumn{2}{|c|}{ HIV seropositive, with transmission $(\mathrm{n}=6)$} & \multicolumn{2}{|c|}{ HIV seropositive, no transmission $(\mathrm{n}=14)$} & \multirow{2}{*}{$\frac{P \text { P-value }}{<0.05}$} \\
\hline & 4 & $67 \%$ & 1 & $7 \%$ & \\
\hline Villitis & 0 & $0 \%$ & 1 & $7 \%$ & NS \\
\hline Villous stromal fibrosis & 2 & $33 \%$ & 3 & $21 \%$ & NS \\
\hline Placental infarction & 2 & $33 \%$ & 2 & $14 \%$ & NS \\
\hline Abnormal villous maturity & 0 & $0 \%$ & 0 & $0 \%$ & NS \\
\hline Acute deciduitis & 5 & $83 \%$ & 6 & $43 \%$ & NS \\
\hline Plasmacellular deciduitis & 3 & $50 \%$ & 1 & $7 \%$ & $<0.05$ \\
\hline Decidual necrosis & 6 & $100 \%$ & 3 & $21 \%$ & $<0.01$ \\
\hline
\end{tabular}

\section{Discussion}

The mechanism and timing of mother-to-child transmission of HIV-1 is complex and presumably multifactorial. Only a few studies have included an examination of the placenta, and the majority of these are from full-term births. The situation in the early gestational period is poorly studied. Moreover, almost all studies are based on HIV subtype B, and whether the same conclusions apply for other subtypes is unknown. The novel aspects of our study include pathologic data from the early gestational period, including placenta and fetal tissues, based on subtype $\mathrm{E}$, which is the predominant form in Asia.

We first analyzed whether there were pathologic changes in the placenta early in gestation that correlated with HIV seropositivity, through a comparison to placentas from seronegative cases of similar gestational age. Other studies on term placentas from HIV subtype B-infected women have shown conflicting results, including increased ${ }^{31}$ and decreased $^{32}$ placental weight; decreased prevalence of villitis, ${ }^{20}$ increased prevalence of chorioamnionitis, ${ }^{17,33,34}$ villous immaturity, ${ }^{35}$ or no placental differences associated with HIV. ${ }^{21,34,36,37}$ The only study to examine subtype $\mathrm{E}$ found term placentas from HIV-infected women were more likely to have chorioamnionitis and deciduitis and less likely to have villitis. ${ }^{28}$ We found in the early gestational period that there were no significant differences with respect to presence of chorioamnionitis, villitis, villous stromal fibrosis, infarction, abnormal villous maturation, deciduitis or decidual necrosis between seropositive and seronegative cases. We also carried out a grading system of chorioamnionitis as done by others ${ }^{28}$ based on the number of acute inflammatory cells. The clinical significance of grading chorioamnionitis in this way is questionable. ${ }^{37}$ We did not find this endeavour informative; severe inflammation was comparable in both seropositive and seronegative groups, and mild to moderate inflammation was actually less common in the seropositive group.

Given that we were unable to identify any pathologic changes in the placenta specific to HIV, we sought to determine if there were changes associated with HIV transmission to the fetus. The few available studies including placental pathology have concluded that there is an increased frequency chorioamnionitis in term placentas in cases of perinatal HIV transmission. ${ }^{17-20,31,38-40}$ This work is based on HIV subtype B, whereas the one study on subtype E concluded that chorioamnionitis was not a risk factor for HIV transmission in the perinatal period. ${ }^{28}$ In our study, we found a significant correlation between HIV subtype E transmission to the fetus and the presence of chorioamnionitis, decidual cell necrosis, and plasmacellular deciduitis, as well as an increased tendency for acute deciduitis. This is the first report of an association of chorioamnionitis in early gestational period with in utero transmission of HIV.

Confirmation of viral infection by HIV was achieved in our study by immunohistochemistry and in situ PCR, techniques that allowed identification of infected cells. In situ PCR was more sensitive in detection of HIV in placentas and equally sensitive in detection of HIV in fetal tissues. However, each technique identified positive cases that the other technique missed. For this reason, we performed both in this study, in order to maximize the identification of cases with HIV viral transmission. We found that about $30 \%$ of fetuses from seropositive mothers showed infection of cells by HIV subtype E. This figure is comparable to the values of $25-47 \%$ from previous reports based on subtype $\mathrm{B}^{6,25,41}$ We also found up to $83 \%$ of placentas were infected with HIV subtype E, compared to results of $28-45 \%$ of term placentas from cases of subtype B. ${ }^{42,43}$ Whether this is a significant difference between subtypes remains to be confirmed. In the placenta, both maternal and fetal-derived cells were involved, and showed a similar spectrum of involvement as in studies by others on HIV subtype B, including decidua, endothelial cells, trophoblast, villous stromal cells and Hofbauer cells. ${ }^{26,42,43}$

The higher frequency of involvement in the placenta compared to the fetus suggests the placenta becomes infected before the fetus. Transmission of HIV from infected cells via the placenta into the fetal circulation is a reasonable route of infection. However, the infected fetal tissues included the lung, intestine and brain, which are all exposed to amniotic fluid at some point during gestation, 
raising the possibility of an amniotic fluid route of infection. It is of interest to note that transmission of HIV to the fetus was significantly associated with chorioamnionitis in our study. Our previous work has shown that inflammation is found in over $80 \%$ of vaginal mucosal biopsies from asymptomatic HIV1 subtype E-infected patients and that Langerhans cells in this site can serve as a reservoir for HIV. ${ }^{4}$ Hence, chorioamnionitis may facilitate infection of the fetus. This might occur through increased exposure to inflammatory cells infected by HIV, increased cytokine release as part of the inflammatory process, or upregulation of cell surface receptor expression. Further studies are required to investigate the role of chorioamnionitis in HIV transmission. As a corollary, this may provide a rationale for prophylactic treatment with antibiotics to prevent chorioamnionitis. ${ }^{45-47}$ Such treatment might have beneficial effects in reducing HIV transmission to the fetus or infant.

In our study, the $30 \%$ of fetuses infected with HIV ranged from 11 to 20 weeks gestational age. For subtype B, the earliest demonstration, using in situ hybridization, was at 8 weeks gestation. ${ }^{26}$ The figure of $30 \%$ was also obtained in a study based on second trimester fetuses. ${ }^{25}$ Since this same figure is often stated for the number of full-term infants infected by mothers with HIV, ${ }^{1}$ it follows that many pediatric HIV infections can be accounted for by transmission during the early gestational period. Not all of these will come to term, of course, and perinatal infection is likely still an important time of viral transmission, as is believed by most. ${ }^{3-6}$ Antiretroviral therapy is usually initiated near to the time of birth based on the concept that most infections are perinatal. Our results show that HIV transmission occurs in the early gestational period, perhaps as often as in the perinatal period. Such cases might not respond as well to antiretroviral therapy that is only started in the perinatal period and may explain the cases of in utero transmission that persist despite antiretroviral prophylaxis. Whether increased benefit would come from earlier administration of this type of therapy remains to be determined.

\section{Acknowledgements}

This work was supported by the Thailand National Center for Genetic Engineering and Biotechnology (BIOTEC). We also wish to thank our technician, Ms Lukana Eianleng, without whom this project could not have been done.

\section{References}

1 Oxtoby M. Perinatally acquired human immunodeficiency virus infection. Pediatr Infect Dis J 1990;9: 609-619.
2 Scott G, Fischl M, Klimas N, et al. Mothers of infants with the acquired immunodeficiency syndrome. Evidence for both symptomatic and asymptomatic carriers. JAMA 1985;253:363-366.

3 Minkoff $\mathrm{H}$, Burns D, Landesman S, et al. The relationship of the duration of ruptured membranes to vertical transmission of human immunodeficiency virus. Am J Obstet Gynecol 1995;173:858-859.

4 Bryson Y. Perinatal HIV-1 transmission: recent advances and therapeutic interventions. AIDS 1996; 10(Suppl 3):S33-S42.

5 Kuhn L, Abrams E, Matheson P, et al. Timing of maternal-infant HIV transmission: associations between intrapartum factors and early polymerase chain reaction results. New York City Perinatal HIV Transmission Collaborative Study Group. AIDS 1997;11:429-435.

6 Mock P, Shaffer N, Bhadrakom C, et al. Maternal viral load and timing of mother-to-child HIV transmission, Bangkok, Thailand. Bangkok Collaborative Perinatal HIV Transmission Study Group. AIDS 1999;13: 407-414.

7 Douglas G, King B. Maternal-fetal transmission of human immunodeficiency virus: a review of possible routes and cellular mechanisms of infection. Clin Infect Dis 1992;15:678-691.

8 Hoff R, Berardi V, Weiblen B, et al. Seroprevalence of human immunodeficiency virus among childbearing women. Estimation by testing samples of blood from newborns. N Engl J Med 1988;318:525-530.

9 Anderson V. The placental barrier to maternal HIV infection. Obstet Gynecol Clin North Am 1997;24: 797-820.

10 Halsey N, Boulos R, Holt E, et al. Transmission of HIV1 infections from mothers to infants in Haiti. Impact on childhood mortality and malnutrition. The CDS/JHU AIDS Project Team. JAMA 1990;264:2088-2092.

11 Braddick M, Kreiss J, Embree J, et al. Impact of maternal HIV infection on obstetrical and early neonatal outcome. AIDS 1990;4:1001-1105.

12 Adjorlolo-Johnson G, De Cock K, Ekpini E, et al. Prospective comparison of mother-to-child transmission of HIV-1 and HIV-2 in Abidjan, Ivory Coast. JAMA 1994;272:462-466.

13 Lepage P, Van de Perre P, Msellati P, et al. Mother-tochild transmission of human immunodeficiency virus type 1 (HIV-1) and its determinants: a cohort study in Kigali, Rwanda. Am J Epidemiol 1993;137:589-599.

14 Bobat R, Coovadia H, Coutsoudis A, et al. Determinants of mother-to-child transmission of human immunodeficiency virus type 1 infection in a cohort from Durban, South Africa. Pediatr Infect Dis J 1996; 15:604-610.

15 Newell M, Dunn D, Peckham C, et al. Vertical transmission of HIV-1: maternal immune status and obstetric factors. The European Collaborative Study. AIDS 1996;10:1675-1681.

16 Andiman W. Transmission of HIV-1 from mother to infant. Curr Opin Pediatr 2002;14:78-85.

17 Ryder R, Nsa W, Hassig S, et al. Perinatal transmission of the human immunodeficiency virus type 1 to infants of seropositive women in Zaire. N Engl J Med 1989; 320:1637-1642.

18 St Louis M, Kamenga M, Brown C, et al. Risk for perinatal HIV-1 transmission according to maternal immunologic, virologic, and placental factors. JAMA 1993;269:2853-2859. 
19 Temmerman M, Nyong'o A, Bwayo J, et al. Risk factors for mother-to-child transmission of human immunodeficiency virus-1 infection. Am J Obstet Gynecol 1995;172(2, Part 1):700-705.

20 Wabwire-Mangen F, Gray R, Mmiro F, et al. Placental membrane inflammation and risks of maternal-to-child transmission of HIV-1 in Uganda. J Acquir Immune Defic Syndr 1999;22:379-385.

21 Ladner J, Leroy V, Hoffman P, et al. Chorioamnionitis and pregnancy outcome in HIV-infected African women. Pregnancy and HIV Study Group. J Acquir Immune Defic Syndr Hum Retrovirol 1998;18: 293-298.

22 Lapointe N, Michaud J, Pekovic D, et al. Transplacental transmission of HTLV-III virus. $\mathrm{N}$ Engl J Med 1985;312:1325-1326.

23 Jovaisas E, Koch M, Schafer A, et al. LAV/HTLV-III in 20-week fetus. Lancet 1985;2:1129.

24 Sprecher S, Soumenkoff G, Puissant F, et al. Vertical transmission of HIV in 15-week fetus. Lancet 1986;2: 288-289.

25 Soeiro R, Rubinstein A, Rashbaum W, et al. Maternofetal transmission of AIDS: frequency of human immunodeficiency virus type 1 nucleic acid sequences in human fetal DNA. J Infect Dis 1992; 166:699-703.

26 Lewis S, Reynolds-Kohler C, Fox H, et al. HIV-1 in trophoblastic and villous Hofbauer cells, and haematological precursors in eight-week fetuses. Lancet 1990;335:565-568.

27 Artenstein A, Coppola J, Brown A, et al. Multiple introductions of HIV-1 subtype E into the western hemisphere. Lancet 1995;346:1197-1198.

28 Schwartz D, Sungkarat S, Shaffer N, et al. Placental abnormalities associated with human immunodeficiency virus type 1 infection and perinatal transmission in Bangkok, Thailand. J Infect Dis 2000;182: 1652-1657.

29 Quiros E, Garcia F, Gonzalez I, et al. Diagnosis of HIV-1 infection by PCR with two primer pairs. Eur J Epidemiol 1993;9:426-429.

30 St Louis D, Gotte D, Sanders-Buell E, et al. Infectious molecular clones with the nonhomologous dimer initiation sequences found in different subtypes of human immunodeficiency virus type 1 can recombine and initiate a spreading infection in vitro. J Virol 1998; 72:3991-3998.

31 Jauniaux E, Nessmann C, Imbert M, et al. Morphological aspects of the placenta in HIV pregnancies. Placenta 1988;9:633-642.

32 Gichangi P, Nyongo A, Temmerman M. Pregnancy outcome and placental weights: their relationship to HIV-1 infection. East Afr Med J 1993;70: 85-89.

33 Mwanyumba F, Gaillard P, Inion I, et al. Placental inflammation and perinatal transmission of HIV-1. J Acquir Immune Defic Syndr 2002;29:262-269.
34 Chandwani S, Greco M, Mittal K, et al. Pathology and human immunodeficiency virus expression in placentas of seropositive women. J Infect Dis 1991;163: 1134-1138.

35 Backe E, Jimenez E, Unger M, et al. Vertical human immunodeficiency virus transmission: a study of placental pathology in relation to maternal risk factors. Am J Perinatol 1994;11:326-330.

36 Temmerman M, Chomba E, Ndinya-Achola J, et al. Maternal human immunodeficiency virus-1 infection and pregnancy outcome. Obstet Gynecol 1994;83: 495-501.

37 Benirschke K, Kaufmann P. Pathology of the Human Placenta. 4th edn. Springer-Verlag: New York, 2000.

38 Kumar R, Uduman S, Khurranna A. A prospective study of mother-to-infant HIV transmission in tribal women from India. J Acquir Immune Defic Syndr Hum Retrovirol 1995;9:238-242.

39 Van Dyke R, Korber B, Popek E, et al. The Ariel Project: A prospective cohort study of maternal-child transmission of human immunodeficiency virus type 1 in the era of maternal antiretroviral therapy. J Infect Dis 1999;179:319-328.

40 Stringer J, Goldenberg R. Subclinical chorioamnionitis as a targetable risk factor for vertical transmission of HIV-1. Ann NY Acad Sci 2000;918:77-83.

41 Young N, Shaffer N, Chaowanachan T, et al. Early diagnosis of HIV-1-infected infants in Thailand using RNA and DNA PCR assays sensitive to non-B subtypes. J Acquir Immune Defic Syndr 2000;24: 401-407.

42 Martin A, Brady K, Smith S, et al. Immunohistochemical localization of human immunodeficiency virus p24 antigen in placental tissue. Hum Pathol 1992;23: 411-414.

43 Mattern C, Murray K, Jensen A, et al. Localization of human immunodeficiency virus core antigen in term human placentas. Pediatrics 1992;89:207-209.

44 Bhoopat L, Eiangleng L, Rugpao S, et al. In vivo identification of Langerhans and related dendritic cells infected with HIV-1 subtype E in vaginal mucosa of asymptomatic patients. Mod Pathol 2001;14: 1263-1269.

45 Goldenberg R, Vermund S, Goepfert A, et al. Choriodecidual inflammation: a potentially preventable cause of perinatal HIV-1 transmission? Lancet 1998; 352:1927-1930.

46 Lamont R, Duncan S, Mandal D, et al. Intravaginal clindamycin to reduce preterm birth in women with abnormal genital tract flora. Obstet Gynecol 2003;101: 516-522.

47 Ugwumadu A, Manyonda I, Reid F, et al. Effect of early oral clindamycin on late miscarriage and preterm delivery in asymptomatic women with abnormal vaginal flora and bacterial vaginosis: a randomised controlled trial. Lancet 2003;361:983-988. 